Research paper

\title{
Significance of the secondary pores in perthite for oil storage and flow in tight sandstone reservoir
}

\author{
Shuheng Dü a,b,*, Yapu Zhao ${ }^{\mathrm{a}, \mathrm{c}, * *}$, Jun Jin ${ }^{\mathrm{d}, \mathrm{e}}$, Gen Kou ${ }^{\mathrm{d}, \mathrm{e}}$, Yongmin Shi ${ }^{\mathrm{f}}$, Xianfu Huang ${ }^{\mathrm{a}}$ \\ ${ }^{a}$ State Key Laboratory of Nonlinear Mechanics, Institute of Mechanics, Chinese Academy of Sciences Beijing, 100190, China \\ ${ }^{\mathrm{b}}$ State Key Laboratory of Oil and Gas Reservoir Geology and Exploitation (Chengdu University of Technology), Chengdu, 610059, China \\ ${ }^{\mathrm{c}}$ School of Engineering Science, University of Chinese Academy of Sciences, Beijing, 100049, China \\ ${ }^{\mathrm{d}}$ Xinjiang Laboratory of Petroleum Reserve in Conglomerate, Karamay, 834000, Xinjiang, China \\ ${ }^{\mathrm{e}}$ Research Institute of Experiment and Detection of PetroChina Xinjiang Oilfield Company, Karamay, 834000, Xinjiang, China \\ ${ }_{\mathrm{f}}^{\mathrm{f}}$ Institute of Oil and Gas Institute, Peking University, Beijing, 100871, China
}

\section{A R T I C L E I N F O}

\section{Keywords:}

Perthite

Tight sandstone

K-feldspar

Na-feldspar

Unconventional oil reservoir

\begin{abstract}
A B S T R A C T
Perthite is a special type of skeleton mineral in tight oil sandstone which cannot be ignored. However, few attention was paid to the secondary pores in perthite and their contributions in tight oil reservoir. This study reveals the perthite's significance in unconventional oil flow characterizes comprehensively and quantitativel by combining the Field Emission Scanning Electron Microscope (FE-SEM) with high resolution, Energy Dispersive Spectrometer (EDS) analysis, high precision image processing, comprehensive parameters construction and calculation. Typical perthite samples of Chang 7 tight oil reservoir of Ordos basin were selected for this study. Our results demonstrate that the growth of K-feldspar and Na-feldspar in perthite is complementary. The mixing process of the two types of stripes promotes each other rather than inhibiting each other. As to the development of secondary pores of perthite, there are clear differences in the area and number of pores, medium differences in the porosity, radius and perimeter, and small differences in other parameters. The more regular and uniform growth of Na-feldspar, the more likely the perthite is to form regular and normalized secondary pore. At least $56.7 \%$ of the secondary pore of perthite contributes to oil flow in the process of oil migration or development, and its scientific significance cannot be ignored. The conclusion could provide the geological basis for the effective development of the unconventional hydrocarbon reservoirs.
\end{abstract}

\section{Introduction}

Unconventional resources have become the rather weighty alternative field for oil and gas exploration and development. The rapid development of its theory and technology has injected new vitality into the world oil and gas industry. As a typical representative of unconventional reservoirs, tight sandstone oil reservoirs are distinct from conventional sandstone reservoirs with large grain size and good physical properties, and shale reservoirs with very small grain size and poor physical properties. They are with the special characteristics of diagenesis, reservoir formation, reservoir permeability and mineral development (Jia, 2017; Mathews et al., 2017; Lai et al., 2018; Du et al., 2018a,b; Krakowska et al., 2018).

Pore throats, as the main places of hydrocarbon storage and flow, have traditionally been the focus of geologists and engineers. The formation of pore throats is undoubtedly due to the accumulation of mineral particles and their later diagnostic transformation (Nayef et al., 2016; Wang et al., 2016; Du, 2019; Huang et al., 2019). For example, shale contains a large number of organic pores, which are mainly brought about by the cracking of kerogen in shale. Kerogen is a type of dispersed organic matter, which is insoluble in alkali, non-oxidizing acid and non-polar organic solvents in sedimentary rocks. It is a type of macromolecule polymer with no fixed structural expression. Properties of organic pore are closely related to the maturity and actual chemical composition of kerogen (Lin et al., 2017; Wang et al., 2019). Therefore, development of minerals themselves and the mechanism of their influence on pore throats development should also be paid attention to.

$\mathrm{K}$-feldspar and Na-feldspar are isomorphic bodies, which are easy to produce mixed minerals owing to mineral crystallization, metasomatism and later diagenesis (Menegon et al., 2013; Du et al., 2019a,b). When observing the tight sandstone oil reservoir of Chang 7 member of Yanchang Formation of Ordos Basin, we found that perthite is widely

\footnotetext{
* Corresponding author. State Key Laboratory of Nonlinear Mechanics, Institute of Mechanics, Chinese Academy of Sciences, Beijing, 100190, China.

** Corresponding author. State Key Laboratory of Nonlinear Mechanics, Institute of Mechanics, Chinese Academy of Sciences Beijing, 100190, China.

E-mail addresses: dushuheng@imech.ac.cn (S. Du), yzhao@imech.ac.cn (Y. Zhao).
} 


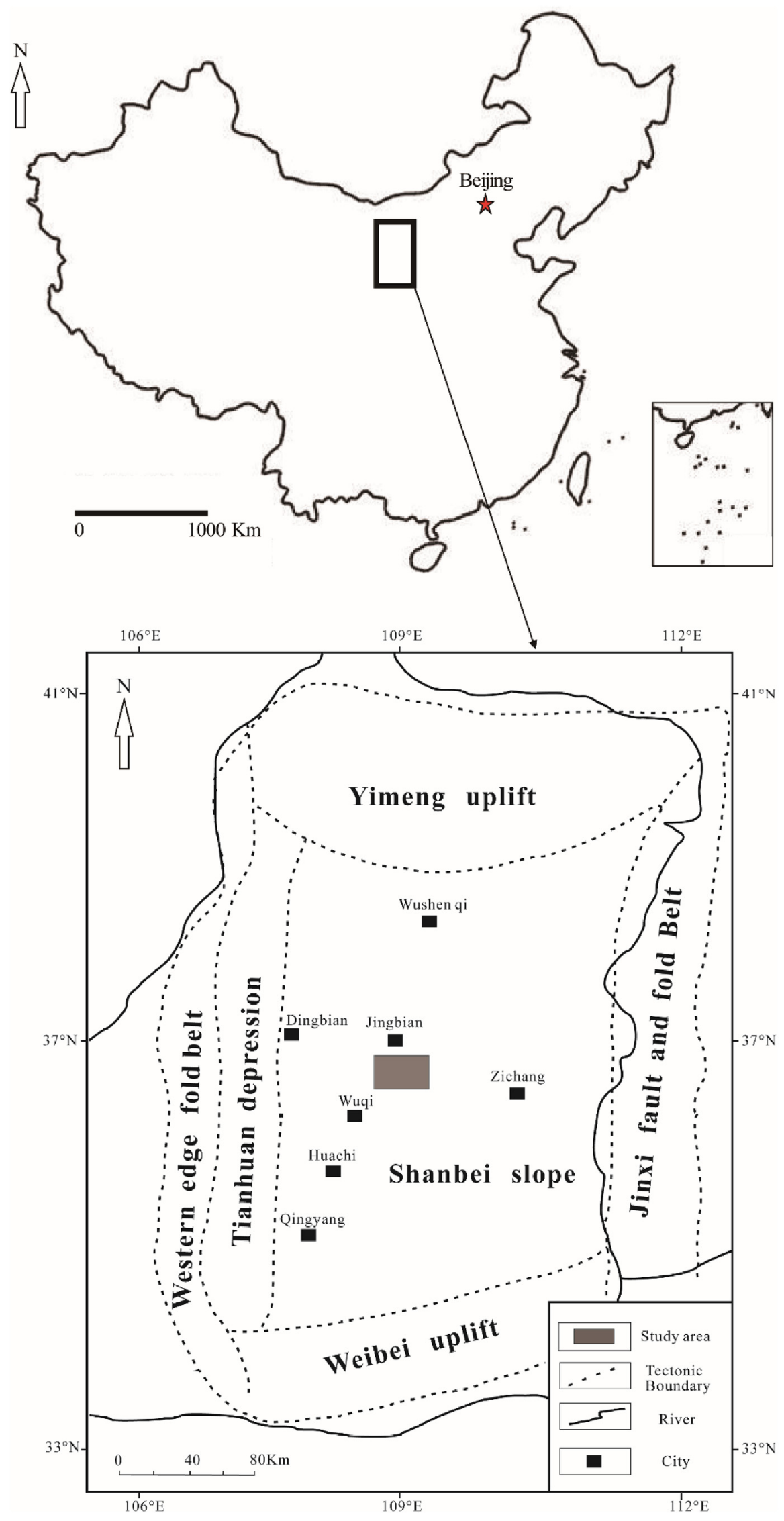

Fig. 1. Location of the study area (Revised from Du et al., 2019a). 


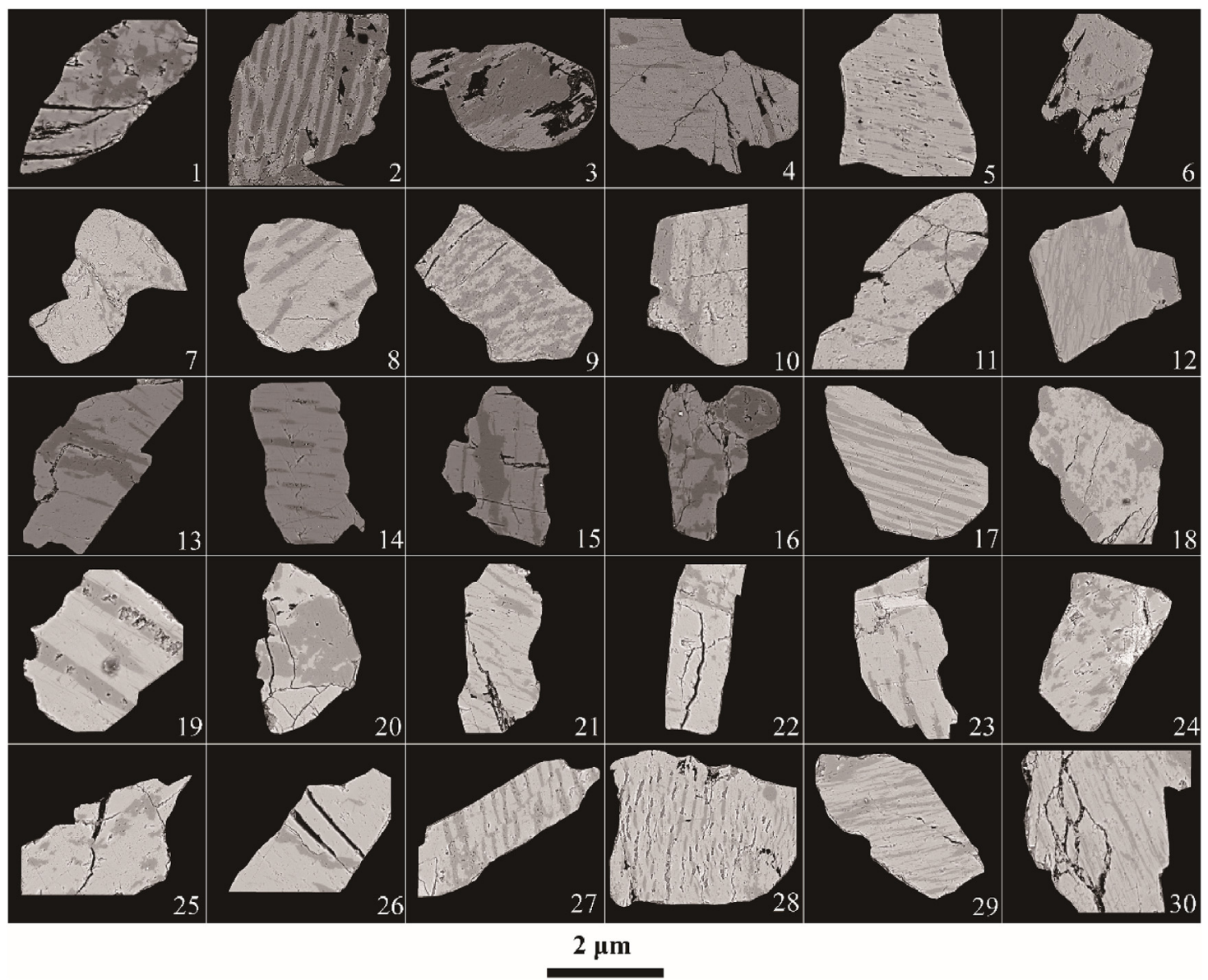

Fig. 2. Collection of perthite samples from tight oil reservoirs and observation by FE-SEM with high resolution.

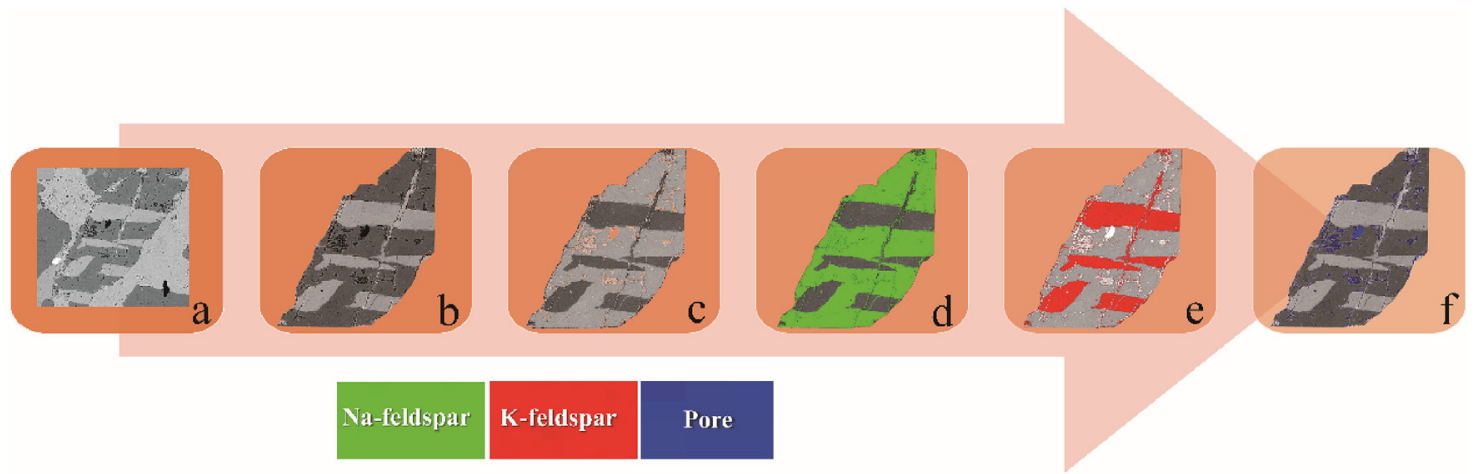

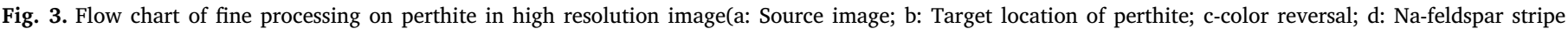
extraction(Green part); e: K-feldspar stripe extraction(Red part); f: Secondary pore extraction (blue part)).

developed as skeleton minerals, and the stripe patterns are different, so the stripe development rules need to be explored. At the same time, the K-feldspar and Na-feldspar stripes in perthite have been dissolved to vary degrees, forming relatively nanometer secondary pores, which are expected to have varying degrees of impact on hydrocarbon storage and permeability. It can be seen from the extensive research works done by predecessors that the academic circles have not paid enough attention to the development of perthite in tight oil reservoirs and the internal relationship between secondary dissolution pore development. The lack of research results has led to the unsolved systematic significance of perthite for tight oil storage and flow.

Feldspar minerals, due to their special lattice structures, would have a critical influence on brittleness and dissolution process (Du et al., 2019a). They are important indicators to judge the degree of reservoir stimulation, and thus lead to a series of scientific issues as follows (Pryer and Robin, 1996; Oelkers and Schott, 1998; Wild et al., 2016; Liu et al., 2017; Yuan et al., 2019; Sun et al., 2019):

(1) Development and regularity of K-feldspar and Na-feldspar in perthite;

(2) Quantitative relationship between K-feldspar and Na-feldspar in perthite and secondary pore formation;

(3) The actual contribution rate of perthite secondary pore of crude oil reservoir and exploitation.

Based on the above problems, in the early studies, Shanmugam 

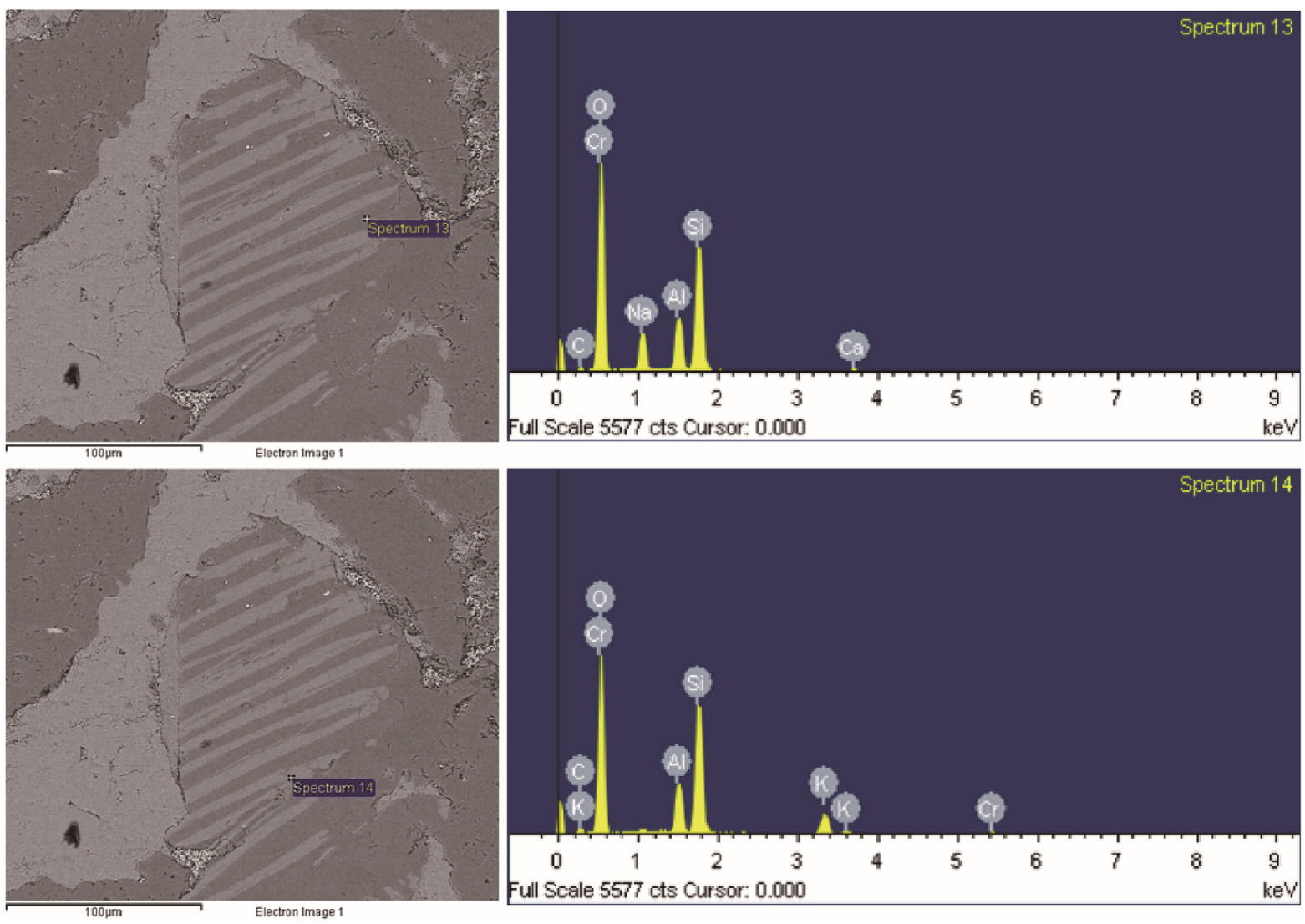

Fig. 4. EDS analysis results of perthite.

(1985) found that the secondary porosities resulting from dissolution of unstable framework grains such as feldspar and rock fragments (including chert) are common in sandstones which proved the significance of feldspar in oil flow include the perthite. Then Milliken (1989) found that vacuolized albite occurring as irregular veins within detrital grains is associated with little visible secondary porosity and forms when precipitation is rapid relative to dissolution of the detrital grain. Huang and Longo, 1992 believed that organic matter plays an important part in promoting feldspar dissolution and secondary pore development. The interface layer properties of fluid $\mathrm{pH}$ and common knowledge surface would have an important influence on feldspar dissolution by combining with dissolution experiments and electron microscopic observation (Welch and Ullman, 1996). Actually, secondary porosity formed by dissolution of K-feldspar can arrive at $11.91 \%$, while that of calcium feldspar is the lowest, being only $0.27 \%$ (Li et al., 2005).

In the recent decade, Sun et al. (2010)found that in clastic reservoirs of Songliao Basin, the selective dissolution of a large number of perthite is obvious, with volume fraction of $4 \%-12 \%$, pore contribution rate of $10 \%-50 \%$, and the dissolution part is mainly main crystal of K-feldspar. Yang et al. (2014) believe that the dissolution rate of feldspar is a function of the $\mathrm{pH}$ of fluid. Meanwhile, the dissolution rate of feldspar matrix grains and the increase of dissolution pore in deep sandstone reservoirs of Bashkichik formation were also quantitatively calculated by large area field emission scanning electron microscopy analysis, and established the growth model of feldspar dissolution pore in deep continental reservoirs with high content feldspar matrix grains (Gao et al., 2017). Relationship between feldspar dissolution and reservoir quality in tight gas reservoirs was proved. (Ma et al., 2017). As to shale gas reservoir, Nie et al. studied the types of dissolution pore in Wufeng Formation and the Longmaxi Formation and found that feldspar dissolution pores are the one of the most important types of dissolution pores (Nie et al., 2019).

Based on the above, this study pays special attention to perthite in
Chang 7 tight oil reservoir of Yanchang Formation in Xin'anbian area of Ordos Basin by means of high resolution field emission SEM imaging, EDS element analysis, high precision image fine processing and attribute parameter construction. 30 typical perthite minerals are chosen as research objects to study stripes in tight oil reservoir. Development and mechanism of feldspar and its secondary pore have been deeply explored, and the contribution of perthite secondary pore to reservoir permeability has been clarified. This will provide an essential geological basis for the principle of tight sandstone reservoir exploitation.

The innovation of this study calls that the special attention should paid to perthite in tight sandstone reservoirs for the first time. The contribution rate of pore in this type of mineral to oil flow has not been studied before, and this research aims to solve this problem.

\section{Geologic setting}

The Ordos Basin, located in the western part of North China Block, is a huge multi-cycle craton basin with simple structure and integrated uplift and subsidence migration. As far as the strata and hydrocarbonbearing strata are concerned, Yanchang Formation is characterized by a large area of the lake delta front and delta plain. The correlation between oil storage and physical properties is high. Horizontal distribution range of sand body controls the distribution range of reservoirs, which is conducive to the formation of large-scale lithologic reservoirs. Reservoir development of Yanchang Formation in Ordos Basin is generally regular. The boundaries between sandstone and mudstone are generally flat. It is easy to distinguish single sand bodies (Jiang et al., 2015). The location of the study area is presented in Fig. 1.

The lithology of the tight sandstone reservoir in Chang 7 member is mainly gray-white siltstone, with the average porosity of $8.5 \%$, the average permeability of $0.22 \times 10^{-3} \mu \mathrm{m}^{2}$ and the average oil saturation of $55 \%$. The distribution of crude oil on the surface of cores is banded, and the oil-bearing properties of each band are obviously 


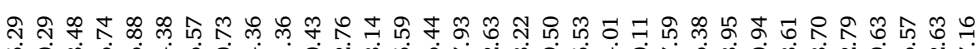

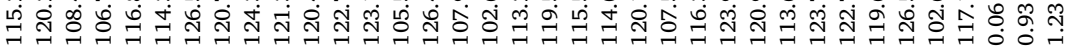

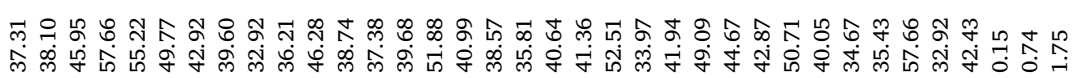

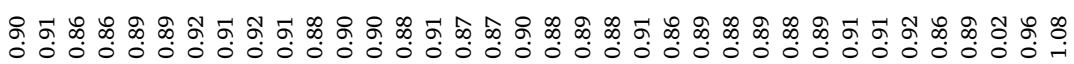

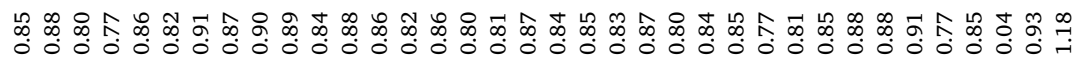

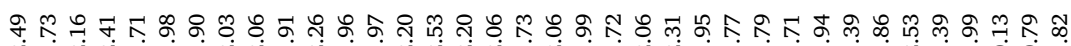
4.

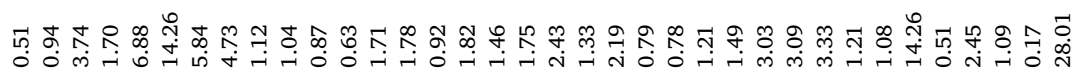

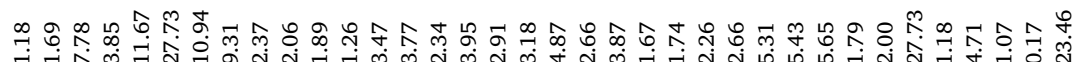

웅 百

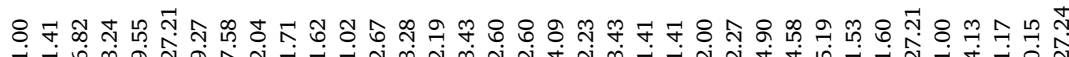

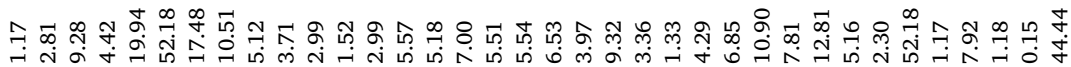

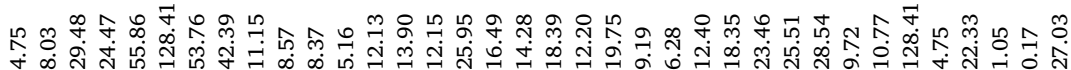

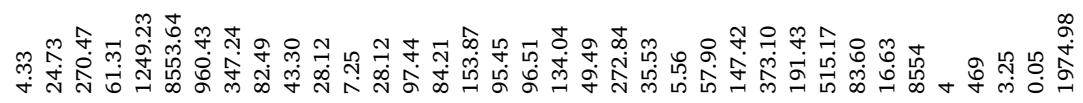

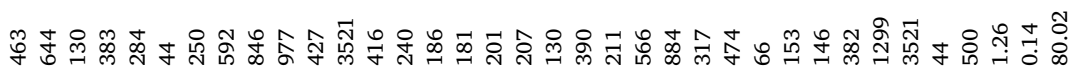

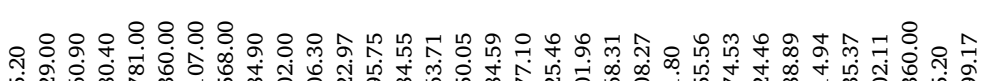
光

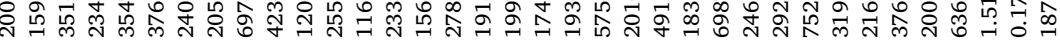




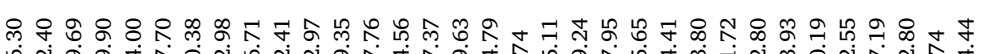

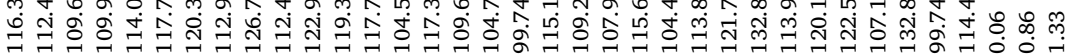

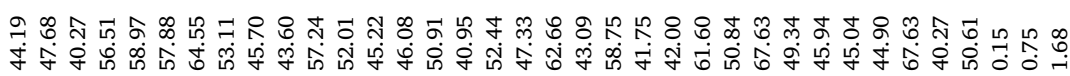

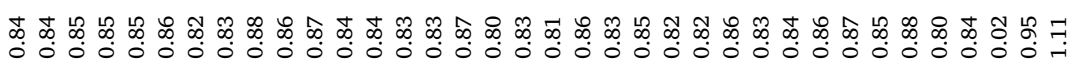

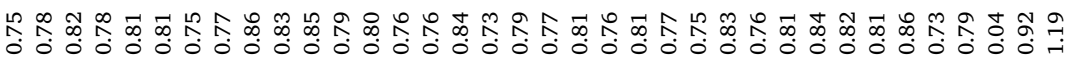

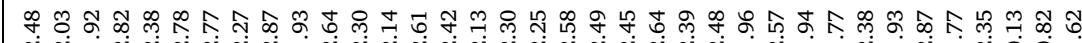

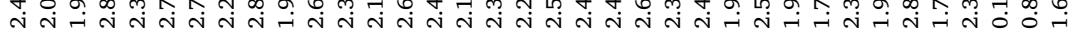

లో o On

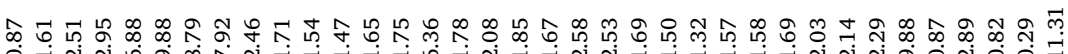

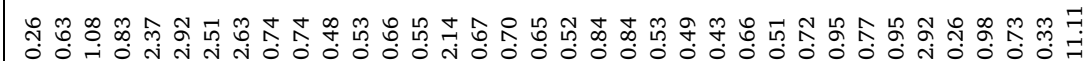

น웅 @

ஜ \&

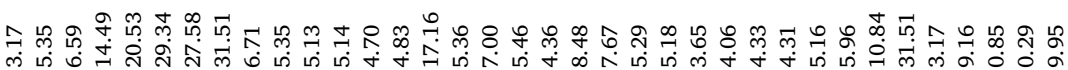

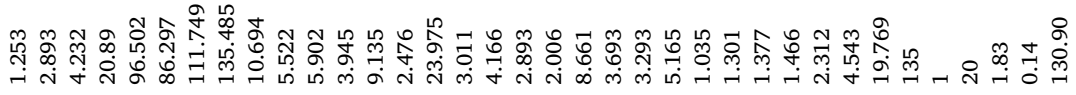

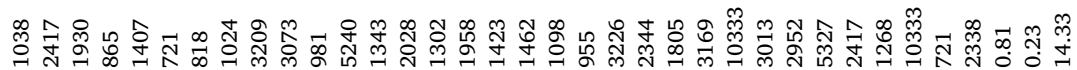
ำ

బै

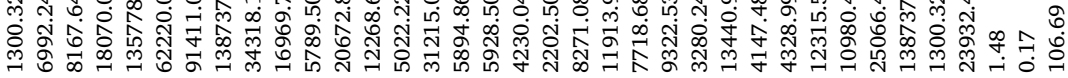




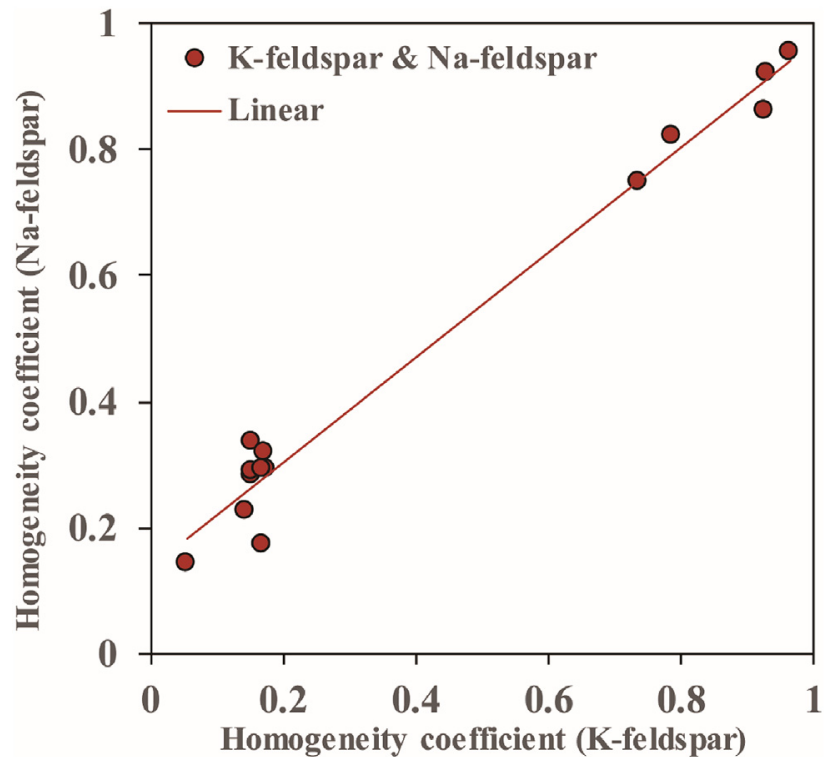

Fig. 5. The correlation between homogeneity coefficients of $K(\mathrm{Na})$-feldspar and the secondary pore parameters of perthite.

dissimilar (Zeng and Li, 2009). Microscopic observation and mineral identification results show that perthite accounts for $68 \%$ of feldspar mineral content and $25 \%$ of the reservoir as a whole. Pore throat size, distribution, structure and other properties will greatly affect the heterogeneity of the reservoir and flow.

\section{Principles and methods}

\subsection{FE-SEM imaging with high resolution}

Generally, the actual resolution of the "High resolution FE-SEM" could reach about $10 \mathrm{~nm}$. Its greatest feature is that it has the ability to observe the scanning images with ultra-high resolution. It is the most effectual instrument for micron-nanometer pore structure testing and morphological observation of reservoirs.

Precise sample preparation and FE-SEM imaging with high resolution were carried out respectively for the tight sandstone oil reservoir of the Chang 7 member of Yanchang Formation. Minerals in which formed the nanopores are accurately identified by Energy Dispersive Spectrometer analysis in order to make the precise positioning of nanopores, effective boundary identification and the comprehensive characterization in the later stage.

It is found that perthite is widely developed in tight oil reservoirs (Fig. 2). There are noticeable differences in stripe morphology, development degree and secondary pore development. The feedback mechanism between perthite and its secondary pore formation requires further exploration.

In order to qualify perthite furtherly, the stripe morphology and secondary pore of 30 typical perthite samples from tight oil reservoir samples were fine extracted by the technology of fine image processing based on adjusting the resolution parameters of FE-SEM (Fig. 3).

Firstly, target location of perthite is carried out by the original image enhancement. The perthite is divided into three categories: Kfeldspar stripe, Na-feldspar stripe and secondary pore by using the algorithm of Inter-mode image segmentation. Secondly, the secondary dissolution pores of K-feldspar and Na-feldspar stripes were extracted separately, the attribute parameters were constructed, the corresponding program was designed for calculation, the statistical and correlation analysis was carried out, and the mechanism was finally analyzed.

It should be pointed out that secondary pore develops in K-feldspar and Na-feldspar stripes, and the positions occupied by secondary pore originally belong to K-feldspar, Na-feldspar stripes or the mixed junction of K-feldspar and Na-feldspar. It is necessary to restore the original appearance of K-feldspar and Na-feldspar stripes before the formation of secondary pore if we want to study the true characteristics of Kfeldspar and Na-feldspar stripes separately.

Based on the technical requirements of the above-mentioned research process, the image gray scale value inversion processing was specially done in this image processing process. The purpose is to reduce the color difference between secondary pore and K-feldspar and Na-feldspar stripes. Then the secondary pore in the stripe can be included in the segmentation of K-feldspar stripes and Na-feldspar stripes, so as to accurately extract the K-feldspar and Na-feldspar which show the original features. This would give a more accurate image basis for subsequent research.

\subsection{Quantitative elements analyses by EDS}

By using EDS technology, a large number of samples of perthite were tested (Fig. 4). The average element content of each sample was taken, and the element composition of perthite in Chang 7 tight sandstone reservoir were summarized.

Quantitative analysis of EDS elements shows That perthite is mainly composed of $\mathrm{KAlSi}_{2} \mathrm{O}_{3}$ and $\mathrm{NaAlSi}_{2} \mathrm{O}_{3}$, with little content of "Ca". The mineral composition is mostly K-feldspar and Na-feldspar, which grow in stripe mosaic. Its growth law and its influence on secondary pore formation need to be explored.

\subsection{Construction and calculation of characterization parameters}

In order to fully quantify the characteristics of perthite, we constructed 14 parameters which are total area, counts, area, perimeter, radius, major axis, minor axis, Feret diameter, minimum of Feret diameter, aspect ratio, circularity, solidity, angle and Feret-angle. Similarly, in order to fully quantify the characteristics of secondary pores in perthite, we used another parameter which is porosity.

Above two kinds of parameters were utilized to quantitatively characterize the secondary pore of perthite and the K-feldspar and Nafeldspar bands in perthite.

\section{Results and discussions}

\subsection{Characterization of perthite}

Thirty typical samples of perthite from tight oil reservoirs were sampled with slices and polished by argon ion. By adjusting the resolution under SEM, 30 samples were imaged with FE-SEM, fine processing of high resolution images and quantitative calculation of attribute parameter. The test and calculation results are as shown in Table 1, Table 2.

Twelve types of parameters show that growth of K-feldspar and Nafeldspar in perthite is obviously different, but it is not without rules. The probability of Na-feldspar existing in the form of independent blocks is generally greater than which of K-feldspar in the formation of single perthite. The area, radius, the perimeter, the major axis, the minor axis, the Feret diameter and the minimum of Feret diameter of Kfeldspar are all higher than those in Na-feldspar. This suggests that the growth intensity of K-feldspar is higher than that of Na-feldspar during the formation of perthite.

Extension angle of the major axis in Legendre ellipse (angle) and extension angle of Feret diameter (Feret-angle) are all robust parameters for quantitatively characterizing the extension direction of $\mathrm{K}$ feldspar and Na-feldspar stripes. The experimental results show that the extension directions of K-feldspar and Na-feldspar are mostly intersected, but the angle values are generally not changed.

Following the concept of reservoir heterogeneity, the concept of 


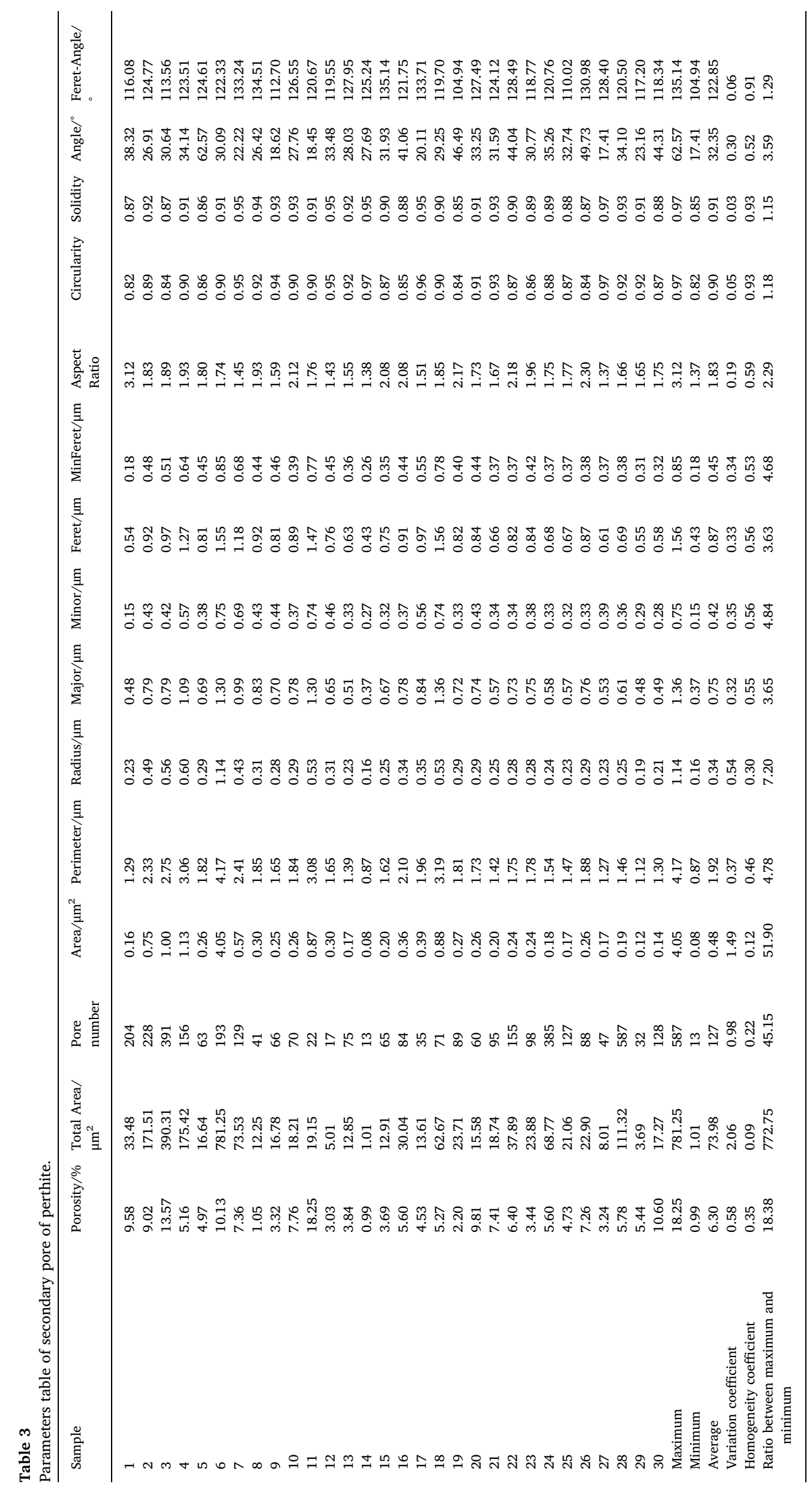




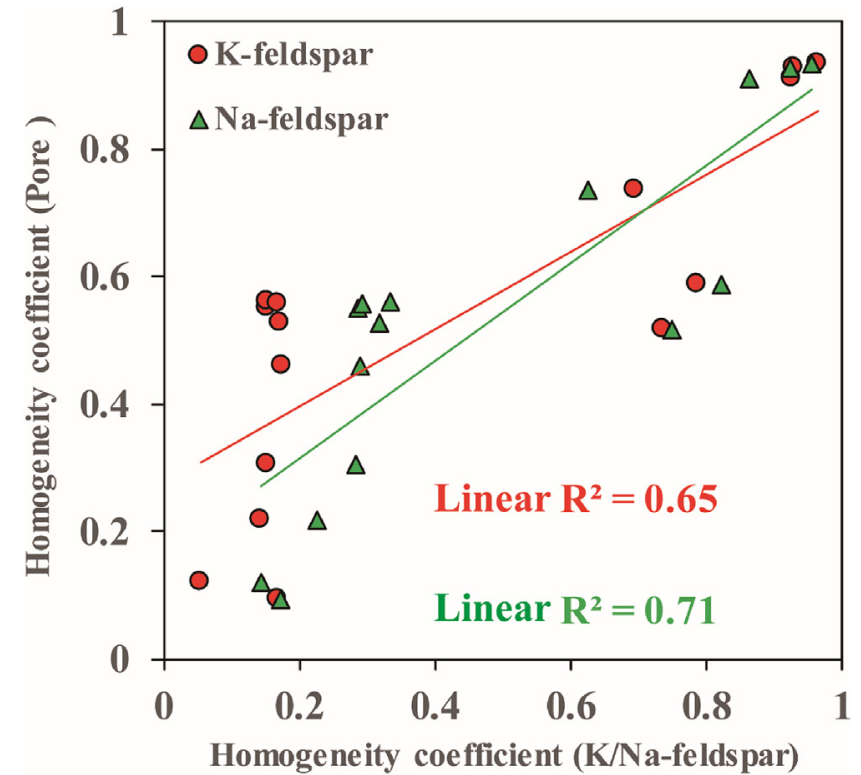

Fig. 6. Correlation analysis of homogeneity coefficient of K-feldspar and Nafeldspar.

homogeneity coefficient was introduced to calculate the homogeneity of K-feldspar and Na-feldspar stripes of all tight oil samples. The difference and relationship of heterogeneity between K-feldspar and Nafeldspar were compared. The homogeneity coefficient is defined as the quotient between the average of any parameter to the maximum of the matching parameter.

It should be pointed out that, according to the statistical principle, the ratio of the average value of the maximum value of a set of data can indicate the homogeneity degree of the data well. Therefore, the construction of this new parameter " $\mathrm{H}$ " can well quantitatively characterize the homogeneity degree of the development of K-feldspar and albite stripes, and it could also provide the data basis for further exploring the influence mechanism of minerals on secondary pore development.

The results in Fig. 5 demonstrates that (Fig. 5) there is a close relationship between the growth of K-feldspar and Na-feldspar in perthite of tight oil reservoir.

The homogeneity of various parameters of Na-feldspar stripe is generally greater than or equal to that of K-feldspar stripe. This shows that the growth of Na-feldspar in perthite is more regular and homogeneous than that of K-feldspar. The homogeneity level of K-feldspar and Na-feldspar promotes each other. With the increase of the homogeneity of $\mathrm{K}(\mathrm{Na})$-feldspar, the $\mathrm{Na}(\mathrm{K})$-feldspar will also increase linearly, but not change from one to the other. The growth of K-feldspar and Na-feldspar in perthite is complementary which has referred in the above text.

\subsection{Development of secondary pore of perthite}

Similarly, the secondary pores of 30 typical perthite samples were quantitatively tested and calculated (Table 3 ).

Results of 15 types of parameters (Table 3) show that the difference of secondary pore development of perthite in each sample is closely related to the type of parameters. Among them, there are obvious differences in the area and number of pores, medium differences in the porosity, radius and perimeter, and slight differences in other parameters.

In this study, it is proved by experiments (Fig. 6) that the development of secondary pore of perthite is controlled by homogeneity of Kfeldspar and Na-feldspar. K-feldspar stripe and Na-feldspar stripe have diverse effects on the development of secondary pore of perthite in terms of homogeneity coefficient. Similarly, homogeneity coefficients of secondary pore parameters were calculated, the heterogeneity of Kfeldspar band, Na-feldspar and secondary pore were compared, respectively, and the relationship between K-feldspar and Na-feldspar on secondary pore was also discussed.

In Fig. 6, the homogeneity of secondary pore of perthite increases linearly with the increase of the homogeneity of parameters of Nafeldspar stripe and K-feldspar stripe. This shows that the more regular and uniform growth of Na-feldspar or K-feldspar stripes, the more likely the perthite is to form regular and normalized secondary pore. This is primarily due to the homogeneity coefficient of mineral stripes can reflect the homogeneity degree of mineral stripes. Similarly, the homogeneity coefficient of secondary pore can reflect the homogeneity degree of secondary pore. As the generation of secondary pore is caused by the dissolution of perthite, the parameters of secondary pore were taken as $\mathrm{X}$-axis, the parameters of perthite were taken as Y-axis, and the correlation between the two parameters was analyzed in order to judge whether the stripes of perthite have influence the formation of secondary pores and the degree of impact.

\subsection{Significance of perthite in unconventional oil storage and flow}

Before obtaining the contribution rate of secondary pore in perthite to oil flow, we need to first understand why secondary pore in perthite would influence oil flow. There is a clear causal and symbiotic

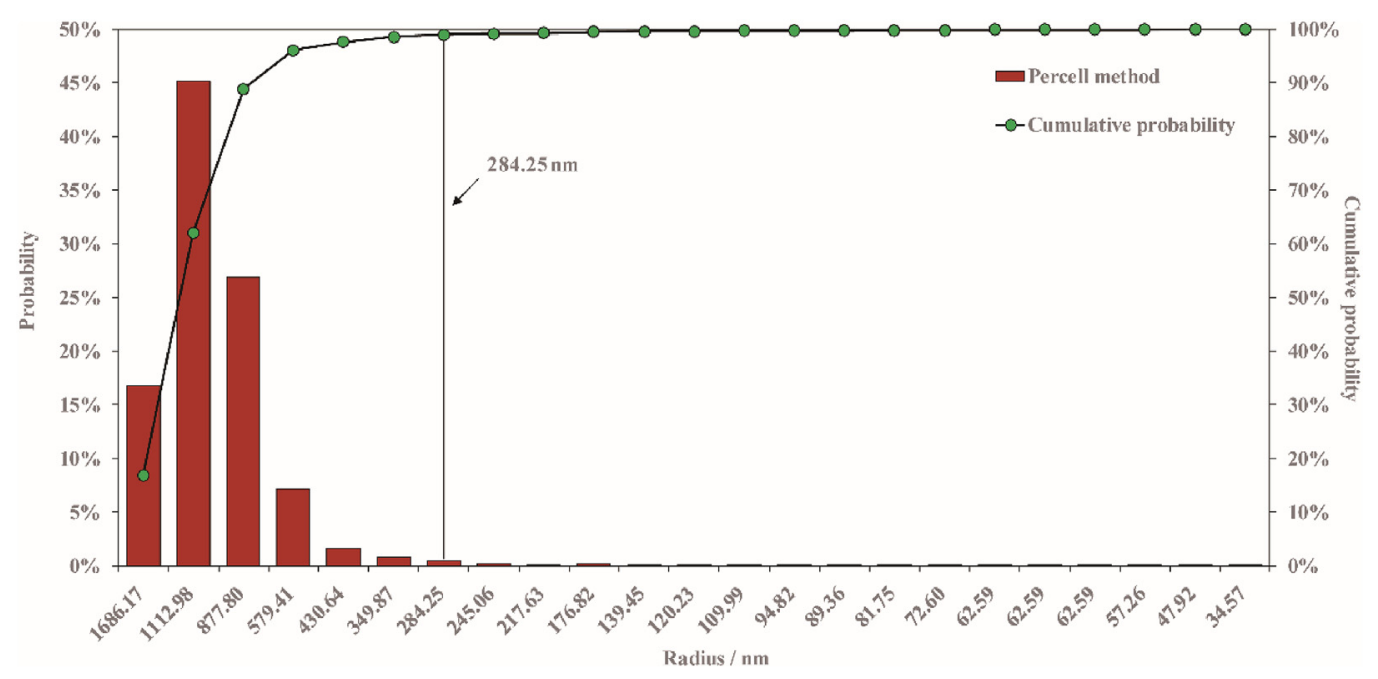

Fig. 7. Determination of dynamic lower limit of pore throats of tight oil reservoir (Purcell method). 


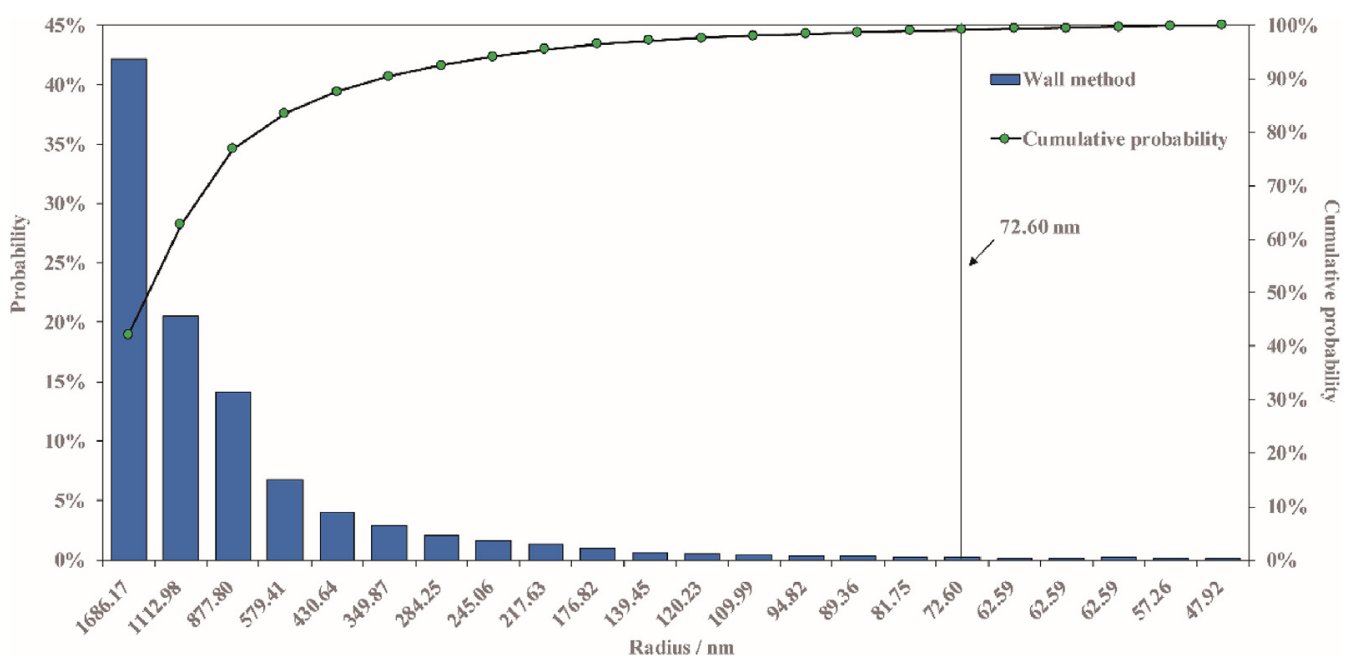

Fig. 8. Determination of dynamic lower limit of pore throats of tight oil reservoir (Wall method).

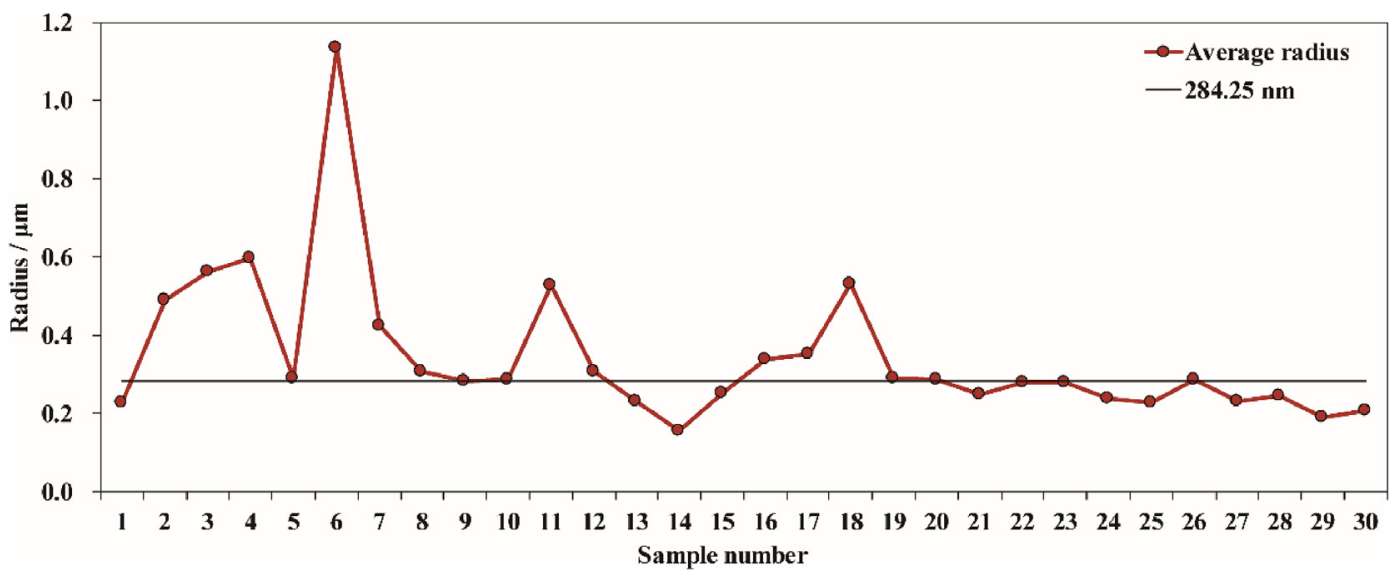

Fig. 9. Statistical histogram of radius of secondary pore in perthite of Chang 7 tight oil reservoir samples.

relationship between mineral attributes and their behavior and the formation of various pore types during the deposition process, that is, "no pores without the minerals". The flow of geological fluids in reservoir rocks is a very complicated problem. In the formation process of reservoir, we usually call the flow of oil in the reservoir as filling process; in the process of oil exploitation, we call it seepage process. In the process of hydrocarbon accumulation or natural energy development, oil not only flows along the larger inter-granular pore, but also along the secondary pore when the size of the secondary pore is larger than that of the crude oil molecule. Therefore, the secondary pore of perthite will influence the seepage of crude oil.

As for how to quantitatively clarify how many secondary pores in perthite contribute to the seepage of crude oil, we have designed the following specific technological process. First, the radius distribution of secondary pores in perthite of all samples were calculated by imaging test. Then, the minimum flowable radius of tight sandstone reservoir was calculated by the classical method. If the radius of the secondary pore of the perthite is greater than the minimum flowable radius, it is considered that the secondary pore of perthite contributes to the flow of crude oil. This is the specific technical details of calculating the contribution rate of perthite secondary pore to oil flow.

Compared with the radius values of secondary pore in all perthite, it can be concluded that almost all perthite have the potential of reservoir tight oil in theory, but if the pore is isolated, it may not contribute. Purcell and Wall proposed two methods to determine the lower limit of dynamic pore throats with the help of high pressure mercury injection data respectively (Ouyang, 1994; Sun et al., 2011). According to the high pressure mercury injection data of Chang 7 tight oil reservoir processed by Purcell method and Wall method, the average dynamic lower limit of pore throats is $284.25 \mathrm{~nm}$ and $72.60 \mathrm{~nm}$ respectively, that is, the dynamic lower limit of pore throats of Chang 7 tight oil reservoir is $72.60 \mathrm{~nm}-284.25 \mathrm{~nm}$ (Fig. 7, Fig. 8).

The secondary pores of perthite account for about $25 \%$ of the whole reservoir. By comparing the maximum value of the lower limit $(284.25 \mathrm{~nm})$ with the radius of all the secondary pore of perthite (Fig. 9), it is concluded that at least $56.7 \%$ of the secondary pore of perthite contributes to the oil flow in the process of oil migration or development, and its scientific significance could not be ignored.

\section{Conclusions}

For perthite in the tight sandstone reservoir of Chang 7 member of Yanchang Formation of Ordos Basin, the growth of K-feldspar and Nafeldspar is complementary, and the mixing process of the two stripes promotes each other rather than inhibiting each other.

The development of secondary pore of perthite in tight sandstone reservoirs is controlled by homogeneity of K-feldspar and Na-feldspar strips. The more regular and uniform growth of Na-feldspar stripes, the more likely the perthite is to form regular and normalized secondary pore. The greater the difference in growth of K-feldspar, the more likely the Perthite in which K-feldspar are to form secondary pore with greater difference.

Virtually all secondary pores in perthite in tight sandstone reservoirs have the potential to store tight oil except isolated pore. At 
least $56.7 \%$ of perthite secondary pores could contribute to oil flow during exploitation process, and its scientific significance should be paid full attention to.

\section{Acknowledgements}

This work was jointly supported by Open Fund (Grant No. PLC20190401) of State Key Laboratory of Oil and Gas Reservoir Geology and Exploitation (Chengdu University of Technology), Open Fund (Grant No. KLOR2018-6) of Key Laboratory of Oil and Gas Resources Research, Chinese Academy of Sciences, National Natural Science Foundation of China (NSFC, Grant No. 11702299, 11872363, 51861145314), the Chinese Academy of Sciences Interdisciplinary Innovation Team Project, the CAS Key Research Program of Frontier Sciences (Grant No. QYZDJ-SSW-JSC019), and the CAS Strategic Priority Research Program (Grant No. XDB22040401). Thanks very much for Prof. Yin Zhang and Dr. Xiaojiao Zheng's great assistance in language polishing.

\section{Appendix A. Supplementary data}

Supplementary data to this article can be found online at https:// doi.org/10.1016/j.marpetgeo.2019.07.006.

\section{References}

Du, S.H., 2019. Prediction of permeability and its anisotropy of tight oil reservoir via precise pore-throat tortuosity characterization and "umbrella deconstruction" method. J. Pet. Sci. Eng. 178, 1018-1028.

Du, S.H., Pang, S., Shi, Y.M., 2018a. A new and more precise experiment method for characterizing the mineralogical heterogeneity of unconventional hydrocarbon reservoirs. Fuel 232, 666-671.

Du, S.H., Pang, S., Shi, Y.M., 2018b. Quantitative characterization on the microscopic pore heterogeneity of tight oil sandstone reservoir by considering both the resolution and representativeness. J. Pet. Sci. Eng. 169, 388-392.

Du, S.H., Shi, G.X., Yue, X.J., Kou, G., Zhou, B., Shi, Y.M., 2019a. Imaging-based characterization of perthite in the upper Triassic Yanchang Formation tight sandstone of the Ordos basin, China. Acta Geol. Sin. Engl. Ed. 93 (2), 373-385.

Du, S.H., Xu, F., Abitkazy, T., Zhou, B., Kou, G., Shi, Y.M., 2019b. Anisotropy characteristics of element composition in Upper Triassic "Chang 8" shale in Jiyuan district of Ordos Basin, China: Microscopic evidence for the existence of predominant fracture zone. Fuel 253, 685-690.

Gao, Z.Y., Feng, J.R., Cui, J.G., Wang, X.Q., Zhou, C.M., Shi, Y.X., 2017. Physical simulation and quantitative calculation of increased feldspar dissolution pores in deep reservoirs. Petrol. Explor. Dev. 44 (3), 387-398.

Huang, W.L., Longo, J.M., 1992. The effect of organics on feldspar dissolution and the development of secondary porosity. Chem. Geol. 98 (3-4), 271-292.

Huang, X.F., Zhao, Y.P., Wang, X.H., Pan, L.S., 2019. Adsorption-induced pore blocking and its mechanisms in nanoporous shale due to interactions with supercritical $\mathrm{CO}_{2}$. J. Pet. Sci. Eng. 178, 74-81.

Jia, C.Z., 2017. Breakthrough and significance of unconventional oil and gas to classical petroleum geology theory. Petrol. Explor. Dev. 44 (1), 1-10.

Jiang, Z.X., Xu, J., Wang, G.T., 2015. The discovery and significance of a sedimentary hiatus within the Carboniferous Taiyuan Formation, northeastern Ordos Basin, China. AAPG Bull. 100, 1067-1072.

Krakowska, P., Puskarczyk, E., Jędrychowski, M., Habrat, M., Madejski, P., Dohnalik, M., 2018. Innovative characterization of tight sandstones from Paleozoic basins in Poland using X-ray computed tomography supported by nuclear magnetic resonance and mercury porosimetry. J. Pet. Sci. Eng. 166, 389-405.
Lai, J., Wang, G.W., Wang, Z.Y., Chen, J., Pang, X.J., Wang, S.H., Zhou, Z.L., He, Z.B., Qin, Z.Q., Fan, X.Q., 2018. A review on pore structure characterization in tight sandstones. Earth Sci. Rev. 177, 436-457.

Li, W.G., Zhang, X.P., Zhong, Y.M., 2005. Formation mechanism of secondary dissolved pores in arcose. Oil Gas Geol. 26 (2), 220-229 (In Chinese with English Abstract).

Lin, K., Yuan, Q.Z., Zhao, Y.P., 2017. Using graphene to simplify the adsorption of methane on shale in MD simulations. Comput. Mater. Sci. 133, 99-107.

Liu, K., Ostadhassan, M., Zhou, J., Gentzis, T., Rezaee, R., 2017. Nanoscale pore structure characterization of the Bakken shale in the USA. Fuel 209, 567-578.

Ma, B.B., Cao, Y.C., Jia, Y.C., 2017. Feldspar dissolution with implications for reservoir quality in tight gas sandstones: evidence from the Eocene Es4 interval, Dongying Depression, Bohai Bay Basin, China. J. Pet. Sci. Eng. 150, 74-84.

Mathews, J.P., Campbell, Q.P., Xu, H., Halleck, P., 2017. A review of the application of X ray computed tomography to the study of coal. Fuel 209, 10-24.

Menegon, L., Stünitz, H., Nasipuri, P., Heilbronner, R., Svahnberg, H., 2013. Transition from fracturing to viscous flow in granulite facies perthitic feldspar (Lofoten, Norway). J. Struct. Geol. 48, 95-112.

Milliken, K.L., 1989. Petrography and composition of authigenic feldspars, Oligocene Frio Formation, south Texas. J. Sediment. Res. 59 (3), 361-374.

Nayef, A., Thomas, J.M., Theis, I.S., 2016. Characterization of petrophysical properties using pore-network and lattice-Boltzmann modelling: choice of method and image sub-size. J. Pet. Sci. Eng. 145, 256-265.

Nie, H.K., Sun, C.X., Liu, G.X., Du, W., He, Z.L., 2019. Dissolution pore types of the Wufeng Formation and the Longmaxi Formation in the Sichuan basin, south China: implications for shale gas enrichment. Mar. Pet. Geol. 101, 243-251.

Oelkers, E.H., Schott, J., 1998. Does organic acid adsorption affect alkali-feldspar dissolution rates? Chem. Geol. 151 (1-4), 235-245.

Ouyang, J., 1994. Oil Logging Interpretation and Reservoir Description. Petroleum Industry Press, Beijing, China.

Pryer, L.L., Robin, P.Y., 1996. Differential stress control on the growth and orientation of flame perthite: a palaeostress-direction indicator. J. Struct. Geol. 18 (9), 1151-1166.

Shanmugam, G., 1985. Significance of secondary porosity in interpreting sandstone composition. AAPG Bull. 69 (3), 378-384.

Sun, F.J., Luo, X., Xiao, J.X., OI, J.S., Shao, M.L., Zeng, F.Y., Zhao, Z.H., 2010. Effect of perthite on the formation of deep clastic reservoir in Songliao basin. J. Xi'an Shiyou Univ. (Natural science edition) 25 (1), 1-8 (In Chinese with English Abstract).

Sun, J.C., Yang, Z.M., Tang, L.G., Yan, Jun, 2011. Study on distribution law of irreducible water and gas saturation of tight sandstone gas reservoir. J. Shenzhen Univ. Sci. Eng. 28 (5), 377-383 (In Chinese with English Abstract).

Sun, W.J.B., Zuo, Y.J., Wu, Z.H., Liu, H., Xi, S.J., Shui, Y., Wang, J., Liu, R.B., Lin, J.Y., 2019. Fractal analysis of pores and the pore structure of the Lower Cambrian Niutitang shale in northern Guizhou province: investigations using NMR, SEM and image analyses. Mar. Pet. Geol. 99, 416-428.

Wang, P.F., Jiang, Z.X., Ji, W.M., Zhang, C., Yuan, Y., Chen, L., Yin, L.S., 2016. Heterogeneity of intergranular, intraparticle and organic pores in Longmaxi shale in Sichuan Basin, South China: evidence from SEM digital images and fractal and multifractal geometries. Mar. Pet. Geol. 72, 122-138.

Wang, X.H., Huang, X.F., Lin, K., Zhao, Y.P., 2019. The constructions and pyrolysis of 3D kerogen macromolecular models: experiments and simulations. Glob. Chall. 3 (5), 1900006.

Welch, S.A., Ullman, W.J., 1996. Feldspar dissolution in acidic and organic solutions: compositional and $\mathrm{pH}$ dependence of dissolution rate. Geochem. Cosmochim. Acta 60 (16), 2939-2948.

Wild, B., Daval, D., Guyot, F., Knauss, K.G., Pollet-Villard, M., Imfeld, G., 2016. PH-dependent control of feldspar dissolution rate by altered surface layers. Chem. Geol. $442,148-159$.

Yang, Y., Min, Y.J., Jun, Y.S., 2014. Effects of Al/Si ordering on feldspar dissolution: Part II. The $\mathrm{pH}$ dependence of plagioclases' dissolution rates. Geochem. Cosmochim. Acta 126, 595-613.

Yuan, G.H., Cao, Y.C., Hans, M.S., Hao, F., Jon, G., Liu, K.Y., Yang, T., Wang, Y.Z., Xi, K.L., Li, F.L., 2019. A review of feldspar alteration and its geological significance in sedimentary basins: from shallow aquifers to deep hydrocarbon reservoirs. Earth Sci. Rev. 191, 114-140.

Zeng, L.B., Li, X.Y., 2009. Fractures in sandstone reservoirs with ultra-low permeability: a case study of the Upper Triassic Yanchang Formation in the Ordos Basin, China. AAPG Bull. 93, 461-477. 